\title{
Genetic Variation in MicroRNAs and Risk of Oral Squamous Cell Carcinoma in South Indian Population
}

\author{
PS Sushma ${ }^{1,2}$, Kaiser Jamil ${ }^{2 *}$, P Uday Kumar ${ }^{1}$, U Satyanarayana ${ }^{3}$, M \\ Ramakrishna $^{4}$, B Triveni ${ }^{4}$
}

\begin{abstract}
Background: MicroRNAs (miRNAs) are small non-coding RNA molecules, implicated in several activities like initiation, progression and prognosis of various cancers. Single nucleotide polymorphisms (SNPs) in miRNA genes can lead to alteration in mRNA expression, resulting in diverse functional consequences. The aim of our study was to investigate the association of miR-149C $>T$ and miR-196a2C $>T$ SNPs with susceptibility to development of oral squamous cell carcinoma (OSCC) in South Indian subjects. Materials and Methods: 100 OSCC patients and 102 healthy controls from the general population were recruited for the study. Genetic analysis was performed by polymerase chain reaction/restriction fragment length polymorphism (PCR/RFLP) as per a standard protocol. Results: The genotype frequencies in miR-196a2 polymorphism, of TT, CT and CC in the OSCC patients were $69 \%, 10 \%$ and $22 \%$ respectively while for control group it was $80 \%, 15 \%$ and $5 \%$ respectively. The $\mathrm{CC}$ genotype of miR196a2 polymorphism was significantly associated with oral squamous cell carcinoma. The genotype frequencies in miR-149 polymorphisms of $\mathrm{CC}, \mathrm{CT}$ and TT in the oral squamous cell carcinoma (OSCC) patients were $72 \%, 22 \%$ and $6 \%$ respectively and for control group $88 \%, 12 \%$ and $0 \%$ respectively. CT and TT genotypes of miR149 polymorphism were found to be significantly associated with OSCC $(p=0.05$ and 0.07$)$. Conclusions: Our study suggests that miR-196a2C $>T$ and miR-149C $>T$ polymorphisms may play crucial roles in the development of OSCC in South Indian subjects.
\end{abstract}

Keywords: miRNA - polymorphisms - oral squamous cell carcinoma - PCR-RFLP - genotypes - South India

Asian Pac J Cancer Prev, 16 (17), 7589-7594

\section{Introduction}

Oral cancer is the sixth most common neoplasm occurring globally and accounts for $30 \%$ of all cancers in India (Elango et al., 2006). Oral cancer may arise as a primary lesion and is reported that about $90 \%$ of oral cancers are squamous cell carcinomas. In the Indian scenario, oral squamous cell carcinoma (OSCC) is the most common cancer in males and it is the third most common cancer in Indian females (Rai et al., 2004). Oral cancer is a disease induced by environment and genetic factors, and the genetic factors include abnormal changes in protein coding genes and non-coding genes such as miRNAs. It is also reported that more than half of the known miRNAs are located in the cancerassociated genomic regions and play an important role in carcinogenesis (Aqeilan et al., 2010).

MicroRNAs (miRNAs) function as important post-transcriptional regulators of mRNA expression by binding to the 3' UTR and resulting in translational repression (Ambros, 2004; Bartel, 2004). It is estimated that at least $30 \%$ of protein coding genes are regulated by miRNAs (Lewis et al., 2005). Alterations of miRNA- coding genes may be of particular importance since a single miRNA regulates a wide spectrum of target genes, a minor change in the function of a miRNA may result in extensive aberrance of tumor-suppressor genes and subsequently contribute to carcinogenesis (Lovat et al., 2011). It is widely accepted that single nucleotide polymorphisms (SNPs) are associated with cancer risk. SNPs occurring in miRNA sequences can therefore affect processing and binding ability of mature mRNAs. The miRNA-associated SNPs can have direct or indirect effect on the protein synthesis. The direct effects include an impairment of miRNA processing or function. Indirect effects are derived from the SNPs in miRNA promoters that affect transcription (Salzman et al., 2013). Recent studies suggest that functional SNPs occurring in miRNA sequences and binding sites of miRNA influences the susceptibility to different cancers. Functional SNPs of miRNA-149 and miRNA-196a2 have been found to be associated with several cancers like breast, colon, liver etc (Jazdzewski et al., 2008; Xu et al., 2008; Yang et al., 2008). We hypothesized that SNPs in these miRNAs may contribute to the susceptibility of OSCC. Our aim was to study the association between miR-149C $>\mathrm{T}$ (rs2292832), 


\section{PS Sushma et al}

and miR-196a2 C>T (rs11614913) polymorphisms in oral squamous cell carcinoma (OSCC) in South Indian subjects.

\section{Materials and Methods}

The study subjects comprised of 100 patients suffering from OSCC and 102 healthy controls. Patients were recruited from the MNJ Institute of Oncology, Hyderabad for a period of 18 months from April 2013. The controls were age and sex matched during the same time period and comprised of healthy volunteers. Using questionnaire the demographic parameters like history of cancer, consumption of alcohol and tobacco chewing habits were recorded. The clinical characteristics were collected from medical records, including tumor differentiation, tumor size, and chemotherapy given. This study was approved by the institutional ethics committee of MNJ Institute of Oncology, and informed consent was obtained from all the participants. Clinical stage of tumor as well as histopathological evaluation was done for confirmation of tumor type.

\section{DNA extraction and genotyping}

Two $\mathrm{ml}$ of venous blood was obtained from each participant (OSCC cases and healthy controls) and DNA was extracted from all the samples using the DNA mini kit (Epicenter Technologies, USA, www.epicenter.com), as directed by the manufacturer's instructions. The concentration of DNA and the purity of each sample were measured by Nano drop 2000c (Thermo Scientific, USA). DNA samples were routinely stored at $-20^{\circ} \mathrm{C}$. Using genomic DNA, miRNA polymorphism was identified by polymerase chain reaction-restriction fragment length polymorphism (PCR-RFLP) (Sheng et al., 2012).

\section{Polymerase chain reaction $(P C R)$}

The primers were synthesized at a commercial facility in Hyderabad (Bioserve, Hyderabad, India). The primers used for amplification of miR-196a2and miR-149 genes (Huang et al., 2013) are listed in Table1.PCR was carried out using a PCR kit (Bioserve) in a total volume of 50 $\mu \mathrm{l}$. The PCR mixture contained $2.5 \mu \mathrm{l}$ of $25 \mathrm{mM} \mathrm{MgCl}$, $10 \mathrm{mMdNTP}$ mixture, $160 \mathrm{pmol}$ of each primer (forward and reverse primers), $0.2 \mu \mathrm{l}$ of Taq $(5 \mathrm{U} / \mu \mathrm{l})$ and a DNA template. The reaction volume was made up to $50 \mu \mathrm{l}$ with sterile water. The PCR reaction was carried out in a IQ5 thermocycler (Bio-Rad, Hercules, CA, USA) using the following optimal conditions. Initial denaturation was carried out at $95^{\circ} \mathrm{C}$ for $5 \mathrm{~min}$, followed by 35 cycles of denaturation at $94^{\circ} \mathrm{C}$ for $35 \mathrm{sec}$, annealing at $61^{\circ} \mathrm{C}$ for $35 \mathrm{sec}$ and extension at $72^{\circ} \mathrm{C}$ for $40 \mathrm{sec}$. After completion of 35 cycles, a final extension step was carried out at $72^{\circ} \mathrm{C}$ for $5 \mathrm{~min}$. The optimized PCR conditions described above were used throughout the study. PCR amplicon size was identified by electrophoresis using $2 \%$ agarose gel containing ethidium bromide under standard electrophoretic conditions. The bands were visualized under UV light, and the gel was imaged using the Gel Dock System (Bio-Imaging System, Hyderabad, India).

\section{Restriction fragment length polymorphism (RFLP)}

The restriction enzymes MspI and PvuII were used to distinguish the miR-196a2C $>\mathrm{T}$ and miR-149C $>\mathrm{T}$ polymorphisms, respectively. In miR-196a2C $>\mathrm{T}$ polymorphism wild-type genotype $\mathrm{CC}$ generated a single band representing the entire $149 \mathrm{bp}$ fragment, the variant genotype TT generated $125 \mathrm{bp}$ and $24 \mathrm{bp}$ fragment and the heterozygote CT genotype displays 3 bands (149, 125 and $24 \mathrm{bp}$ ). In miR-149C $>\mathrm{T}$ polymorphisms wildtype genotype $\mathrm{CC}$ generated a single band representing the entire $254 \mathrm{bp}$ fragment, the variant genotype TT generated 194bp and 60bp fragment and the heterozygote CT genotype displays 3 bands (254, 194 and 60bp). The restriction products were analyzed by electrophoresis on a $3 \%$ agarose gel containing ethidium bromide.

\section{Statistical analysis}

The Fisher's exact test $(2 \times 2$ only) was performed by using MedCalc software for Windows (version 7.4.1.0; Mariakerke, Belgium) to examine the association of miR polymorphisms between cases and controls and different clinical and pathological parameters. The difference between the groups was considered significant if the $\mathrm{P}<0.05$ was less than 0.05 .

\section{Results}

Clinical characteristics of the study population

The highest percentage of OSCC patients were identified between 46-65 years. The age range of OSCC male patients was 26-74 years and for female OSCC patients age ranged from 21-63 years. In the control group, among 102 healthy subjects, 64 males were in the age range of 20-70 years and 38 females were within the age range of $20-50$ years. Regarding the primary tumor site, there was a predominance of buccal mucosa (BM) $(37.33 \%)$, followed by the tongue $(22.0 \%)$, mandible and oral cavity at $12 \%$, and $10 \%$ respectively. In the present study, clinical stage III showed the highest frequency $-(40 \%)$, followed by stage IV-(31.33\%), and stage II (22\%), while stage I (6.67\%), showed very low frequency when compared to other groups (Table-2). All tumor samples were confirmed by histopathological evaluation and included in the study.

Table 1. The Primers used for Amplification of miR-196a and miR-149 Genes

\begin{tabular}{llr}
\hline miRs & \multicolumn{1}{c}{ Primer Sequence } & PCR Product \\
\hline miR-196a2 forward primer: & 5'-CCC CTT CCC TTC TCC TCC AGA TA -3' & 149bp \\
miR-196 a2reverse primer: & 5'-CGA AAA CCG ACT GAT GTA ACT CCG-3'. & $194 \mathrm{bp}$ \\
miR-149 forward primer: & 5'-TGTCTTCACTCCCGTGCTTGTCC-3' & \\
miR-149 reverse primer: & 5'-TGAGGCCCGAAACACCCGTA-3'. \\
\hline
\end{tabular}


miR-196a2C-T polymorphism and OSCC susceptibility

The genotype frequencies of TT, CT and CC in the OSCC patients were $69 \%, 10 \%$ and $22 \%$ and in control group were $80 \%, 15 \%$ and $5 \%$ respectively. No significant difference between the patients and controls for CT genotype was observed $(\mathrm{p}=0.31)$. The adjusted $\mathrm{P}<0.05$ between the patients and controls for the $\mathrm{CC}$ genotype was significant and this shows that there is a relation in risk of OSCC between cases and controls for the miR196a gene polymorphism $(\mathrm{p}=0.001)$ (Table- 3$)$.

Table 2. Demographic and Clinical Profile of the Subjects Recruited

\begin{tabular}{|c|c|c|}
\hline & $\begin{array}{l}\mathrm{n}=100 \\
\text { (cases) }\end{array}$ & $\begin{array}{c}n=102 \\
(\text { Controls })\end{array}$ \\
\hline \multicolumn{3}{|c|}{ Demographic characteristics } \\
\hline \multicolumn{3}{|l|}{ Gender } \\
\hline Males & $61(61 \%)$ & $64(62.74)$ \\
\hline Females & $39(39 \%)$ & $38(37.25)$ \\
\hline \multicolumn{3}{|l|}{ Age distribution } \\
\hline 26-45(years) & $19(19 \%)$ & $29(28.43)$ \\
\hline 46-65(years) & $62(62 \%)$ & $58(56.86)$ \\
\hline 66 and above (years) & $19(19 \%)$ & $15(14.70)$ \\
\hline \multicolumn{3}{|l|}{ Personal habits } \\
\hline Alcoholics & $16(16 \%)$ & - \\
\hline Smokers & $32(32 \%)$ & - \\
\hline Chewing & $52(52 \%)$ & - \\
\hline \multicolumn{3}{|l|}{ Clinical characteristics } \\
\hline \multicolumn{3}{|l|}{ Site of diagnosis } \\
\hline Tongue & $36(36 \%)$ & - \\
\hline Buccal mucosa (BM) & $43(43 \%)$ & - \\
\hline Mandible & $12(12 \%)$ & - \\
\hline Oral cavity & $9(9 \%)$ & - \\
\hline \multicolumn{3}{|l|}{ Staging } \\
\hline Stage 1 & $10(10 \%)$ & - \\
\hline Stage 2 & $19(19 \%)$ & - \\
\hline Stage 3 & $50(50 \%)$ & - \\
\hline Stage 4 & $21(21 \%)$ & - \\
\hline
\end{tabular}

miR-149C-T polymorphism and OSCC susceptibility

The genotype frequencies of miR-149 showed that CC, CT and TT genotypes in the OSCC patients were $72 \%, 22 \%$ and $6 \%$ and for control group were $88 \%, 12 \%$ and $0 \%$ respectively. The adjusted $\mathrm{p}$ value between the patients and controls for the CT and TT genotypes was significant and this shows that there is a relative risk of OSCC between cases and controls for the miR149 gene polymorphism ( $\mathrm{p}=0.05$ and 0.07 ) (Table-4).

Correlation between genotypes and clinicopathological parameters of OSCC

The association between genotypes and clinicopathological parameters of OSCC was also

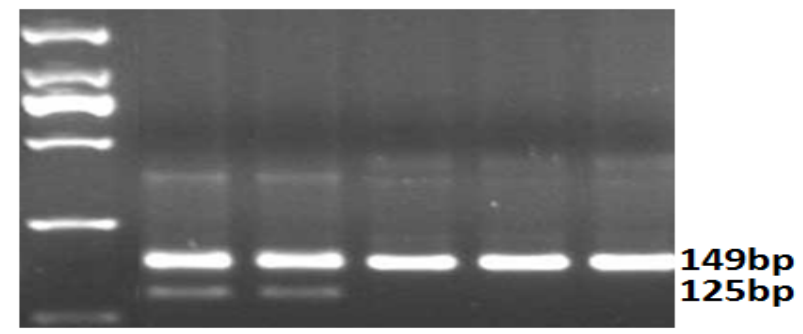

Figure 1. PCR-RFLP Genotyping of SNP miR-196a rs3746444. Lane: 1 - 100bp Ladder, Lane: 2 \& 3 -heterozygous mutations (CT) (149bp, 125bp \& 24bp), Lane: 3-5 Homozygous wild type (149bp)

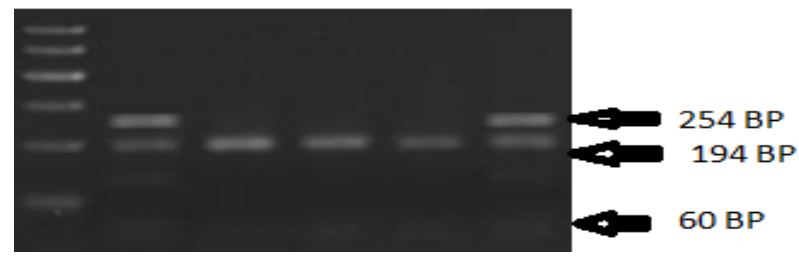

Figure 2. PCR-RFLP genotyping of SNP miR-149 rs3746444. Lane: 1 - 100bp Ladder, Lane: 2 \& 6 - heterozygous mutations (CT) (254bp, 194bp \& 60bp), Lane: 3-5 Homozygous (194bp \& 60bp)

Table 3. Genotypes Distribution for miR196a2 gene Polymorphism in Oral Squamous Cell Carcinoma (OSCC) and Controls

\begin{tabular}{lcccccc}
\hline miR-196a2 genotyping & Cases $(\mathrm{n}=100)$ & Controls $(\mathrm{n}=102)$ & Odds Ratio & 95\% CI & Chi square & $\mathrm{p}$-Value \\
\hline TT & $68(68 \%)$ & $81(80 \%)$ & 0.57 & $0.30-1.09$ & 2.34 & 0.09 \\
CT & $10(10 \%)$ & $15(15 \%)$ & 0.64 & $0.27-1.51$ & 0.64 & 0.31 \\
CC & $22(22 \%)$ & $6(5 \%)$ & 4.51 & $1.74-11.67$ & 9.67 & 0.001 \\
CT/CC & $32(32 \%)$ & $21(20 \%)$ & 1.81 & $0.95-3.34$ & 2.83 & 0.06 \\
TT/CT & $78(78 \%)$ & $96(94 \%)$ & 0.23 & $0.09-0.61$ & 8.7 & 0.003 \\
\hline
\end{tabular}

$\mathrm{p}=<0.05$ (Significant) OR: Odds Ratio, $95 \%$ Confidence intervals, Chi square

Table 4. Genotypes Distribution for miR149 gene Polymorphism in Oral Squamous Cell Carcinoma (OSCC) and Controls

\begin{tabular}{lcccccc}
\hline miR-149 genotyping & Cases $(\mathrm{n}=100)$ & Controls $(\mathrm{n}=102)$ & Odds Ratio & 95\% CI & Chi square & $\mathrm{p}$-Value \\
\hline CC & $72(72 \%)$ & $90(88 \%)$ & 0.34 & $0.16-0.72$ & 7.39 & 0.004 \\
CT & $22(22 \%)$ & $12(12 \%)$ & 2.11 & $0.98-4.55$ & 3.08 & 0.05 \\
TT & $6(6 \%)$ & $0(0.0 \%)$ & 14.1 & $0.78-253.7$ & 4.39 & 0.07 \\
CT/TT & $26(26 \%)$ & $12(12 \%)$ & 2.63 & $1.24-5.59$ & 5.8 & 0.01 \\
CC/CT & $94(94 \%)$ & $102(100 \%)$ & 0.07 & $0.003-1.25$ & 4.39 & 0.07 \\
\hline
\end{tabular}

$\mathrm{p}=<0.05$ (Significant) OR: Odds Ratio, $95 \%$ Confidence intervals, Chi square 
Table 5. Association between miR-196a2 rs3746444 Genotypes and Demographic \& Clinical Characteristics of OSCC Patients

\begin{tabular}{|c|c|c|c|c|c|}
\hline ‘ & $n=100$ & TT & $\mathrm{CT}$ & $\mathrm{CC}$ & P-Value \\
\hline \multicolumn{6}{|c|}{ Demographic characteristics } \\
\hline \multicolumn{6}{|l|}{ Gender } \\
\hline Males & $61(61 \%)$ & $38(62 \%)$ & $8(13 \%)$ & $15(25 \%)$ & 0.61 \\
\hline Females & $39(39 \%)$ & $30(77 \%)$ & $2(5 \%)$ & $7(18 \%)$ & 0.31 \\
\hline \multicolumn{6}{|l|}{ Age distribution } \\
\hline 26-45(years) & $19(19 \%)$ & $16(84 \%)$ & $1(5 \%)$ & $2(11 \%)$ & 0.35 \\
\hline 46-65(years) & $62(62 \%)$ & $39(62 \%)$ & $7(12 \%)$ & $16(26 \%)$ & 0.45 \\
\hline 66 and Above(years) & $19(19 \%)$ & $13(68 \%)$ & $2(10 \%)$ & $4(22 \%)$ & 0.94 \\
\hline \multicolumn{6}{|l|}{ Personal habits } \\
\hline Alcoholics & $16(42 \%)$ & $11(76 \%)$ & $2(10 \%)$ & $3(15 \%)$ & 0.77 \\
\hline Smokers & $32(32 \%)$ & $28(87 \%)$ & $1(3 \%)$ & $3(10 \%)$ & 0.06 \\
\hline Chewing & $52(52 \%)$ & $34(65 \%)$ & $5(10 \%)$ & $13(30 \%)$ & 0.008 \\
\hline \multicolumn{6}{|l|}{ Clinical characteristics } \\
\hline \multicolumn{6}{|l|}{ Site of diagnosis } \\
\hline Tongue & $36(36 \%)$ & $24(66 \%)$ & $3(8 \%)$ & $9(25 \%)$ & 0.74 \\
\hline Buccal mucosa (BM) & $43(43 \%)$ & $24(56 \%)$ & $7(16 \%)$ & $12(27 \%)$ & 0.04 \\
\hline Mandible & $12(12 \%)$ & $12(100 \%)$ & $0(0.0 \%)$ & $0(0.0 \%)$ & 0.29 \\
\hline Oral cavity & $9(9 \%)$ & $8(89 \%)$ & $0(0.0 \%)$ & $1(11 \%)$ & 0.46 \\
\hline \multicolumn{6}{|l|}{ Staging } \\
\hline Stage 1 & $10(10 \%)$ & $10(100 \%)$ & $0(0.0 \%)$ & $0(0.0 \%)$ & 0.37 \\
\hline Stage 2 & $19(19 \%)$ & $12(63 \%)$ & $1(6 \%)$ & $6(31 \%)$ & 0.55 \\
\hline Stage 3 & $50(50 \%)$ & $33(66 \%)$ & $6(12 \%)$ & $11(22 \%)$ & 0.50 \\
\hline Stage 4 & $21(21 \%)$ & $13(62 \%)$ & $3(14 \%)$ & $5(24 \%)$ & 0.43 \\
\hline
\end{tabular}

Table 6. Association between miR-149 rs3746444 Genotypes and Demographic \&Clinical characteristics of OSCC Patients

\begin{tabular}{|c|c|c|c|c|c|}
\hline & $\mathrm{n}=100$ & $\mathrm{CC}$ & $\mathrm{CT}$ & $\mathrm{TT}$ & P-Value \\
\hline \multicolumn{6}{|c|}{ Demographic characteristics } \\
\hline \multicolumn{6}{|l|}{ Gender } \\
\hline Males & $61(61 \%)$ & $41(85 \%)$ & $14(23 \%)$ & $6(10 \%)$ & 0.57 \\
\hline Females & $39(39 \%)$ & $31(79 \%)$ & $8(21 \%)$ & $0(0.0 \%)$ & 0.12 \\
\hline \multicolumn{6}{|l|}{ Age distribution } \\
\hline 26-45(years) & $19(19 \%)$ & $15(79 \%)$ & $4(21 \%)$ & $0(0.0 \%)$ & 0.78 \\
\hline 46-65(years) & $62(62 \%)$ & $45(72 \%)$ & $12(20 \%)$ & $5(8 \%)$ & 0.50 \\
\hline 66 and Above(years) & $19(19 \%)$ & $12(62 \%)$ & $6(33 \%)$ & $1(5 \%)$ & 0.27 \\
\hline \multicolumn{6}{|l|}{ Personal habits } \\
\hline Alcoholics & $16(42 \%)$ & $8(50 \%)$ & $8(50 \%)$ & $0(0.0 \%)$ & 0.008 \\
\hline Smokers & $32(32 \%)$ & $26(87 \%)$ & $6(13 \%)$ & $0(0.0 \%)$ & 0.44 \\
\hline Chewing & $52(52 \%)$ & $38(73 \%)$ & $8(15 \%)$ & $6(12 \%)$ & 0.09 \\
\hline \multicolumn{6}{|l|}{ Clinical characteristics } \\
\hline \multicolumn{6}{|l|}{ Site of diagnosis } \\
\hline Tongue & $36(36 \%)$ & $27(75 \%)$ & $7(19 \%)$ & $2(6 \%)$ & 0.62 \\
\hline Buccal mucosa (BM) & $43(43 \%)$ & $28(65 \%)$ & $11(24 \%)$ & $4(11 \%)$ & 0.05 \\
\hline Mandible & $12(12 \%)$ & $9(75 \%)$ & $3(25 \%)$ & $0(0.0 \%)$ & 0.88 \\
\hline Oral cavity & $9(9 \%)$ & $8(88 \%)$ & $1(12 \%)$ & $0(0.0 \%)$ & 0.37 \\
\hline \multicolumn{6}{|l|}{ Staging } \\
\hline Stage 1 & $10(10 \%)$ & $10(100 \%)$ & $0(0.0 \%)$ & $0(0.0 \%)$ & 0.16 \\
\hline Stage 2 & $19(19 \%)$ & $14(74 \%)$ & $4(21 \%)$ & $1(5 \%)$ & 0.89 \\
\hline Stage 3 & $50(50 \%)$ & $35(70 \%)$ & $12(24 \%)$ & $3(6 \%)$ & 0.62 \\
\hline Stage 4 & $21(21 \%)$ & $13(62 \%)$ & $6(28 \%)$ & $2(10 \%)$ & 0.34 \\
\hline
\end{tabular}

analyzed in our study (Table-5\& Table 6). When miR196a2 and miR149 polymorphisms were correlated with the gender and age, it was noted that there was no significant difference between males, females and age groups. Buccal mucosa (BM) showed a high frequency of cancer development when compared with other sites and we found a relation between carcinoma in buccal mucosa (BM) and CC genotype $(\mathrm{p}=0.04)$ of miR196a2 polymorphism. With reference to the association between the genotype and the clinical staging, no relation between these two polymorphisms and the clinical staging was seen. The observation reveals that patients with CT genotype of miR149 polymorphism showed relationship with personal habits like tobacco chewing $(p=0.008)$. 


\section{Discussion}

MicroRNAs are small non-coding RNA molecules, which participate in diverse biological processes and may regulate tumor suppressor genes or oncogenes. The dysfunction of miRNAs which target oncogenic or tumor suppressor activity may influence the development of cancer (Gregory et al., 2005; Sassen et al., 2008; Kwak et al., 2010; Yoon et al., 2012). Single nucleotide polymorphisms (SNPs) in miRNA may contribute to diverse functional consequences, including cancer development, by altering miRNA expression (Xu et al., 2011). This type of genetic variant may influence the processing of the mature miRNA (Hu et al., 2008). Numerous studies have shown the association between miRNA SNPs and cancer risk. In our study, we performed a case-control study of the two most commonly studied SNPs in miRNA genes, miR-149C $>$ T (rs2292832), and miR-196a2 C>T (rs11614913) to investigate the risk of OSCC in the South Indian population.

Based on the important role of that rs11614913 polymorphism located in the hsa-miR-196a2 3' mature sequence affects the miRNA maturation and its target mRNA possibility (Ryan et al., 2010 and Chu et al., 2011), it is biologically plausible that genetic variants of hsa-miR-196a2 could modulate the susceptibility to cancer. Several studies reported that 196a2 (rs11614913 cytosine to thymine) polymorphism, was associated with multiple kind of cancers, such as lung cancer (TianTian et al., 2009), breast cancer (Lin et al., 2011), gastric cancer (Okubo et al., 2010; Peng et al., 2010; Daehoahn et al., 2013), liver cancer (Peng et al., 2010; Akk1z et al., 2011), glioma (Tonghai et al., 2010), prostate cancer (Ginu et al., 2011), esophageal cancer (Kaiwang et al., 2010, NaWang et al., 2014). When reviewed together, the majority of these studies described significant associations of CC genotype of $196 \mathrm{a} 2$ polymorphism and cancer risk. In the present study, our results also show that CC genotype of miR-196a 2 polymorphism was significantly associated with OSCC $(\mathrm{p}=0.001)$. Similar results were reported in multiple cancers, including squamous cell carcinoma of head and neck (Sheng et al., 2010). We suggest that this polymorphism could play an important role in development and progression of oral squamous cell carcinoma. In addition to cancer risk, this polymorphism may also be associated with poor prognosis (Shen $\mathbf{J}$ et al., 2008).

The single nucleotide polymorphism of miR-149 gene was first reported by $\mathrm{Hu}$ et al. (2008). A C $>\mathrm{T}$ genetic polymorphism was found in the miR-149 gene and was located in the stem region next to the mature miR-149C $>\mathrm{T}$ sequence. Regarding miR-149C $>\mathrm{T}$, it is a proapoptotic miRNA to repress the expression of Akt1 and E2F1. Silencing of Akt1 and E2F1 can induce apoptosis in human tumor cell lines (Lin et al., 2011). Previous studies showed that polymorphism in miR-149C $>$ T can change the expression of mature miRNAs or the binding activities to target mRNA, and thus influence cancer risk through various mechanisms (Liu et al., 2010). Our study found that $\mathrm{CC}$ genotype of miR-149C $>\mathrm{T}$ was associated with risk of OSCC. Similar results were reported in head and neck cancer by Liu et al. (2010). It was also reported that a combined risk genotype of two SNPs on miR-149, and miR-196a2 was found to be significantly associated with cancer risk. We postulate that this type of genetic variants may influence the processing of the mature miRNA for translational repression.

The association between genotypes and clinicopathological parameters of OSCC was also analyzed in our study. It was noted that there was no significant association between miR196a 2 and miR149 polymorphisms with gender or age. The frequency of TT genotypes in miR196a showed higher frequency in advanced stages of OSCC when compared to early stage. We suggest that TT OSCC patients seem to have more advanced tumor progression. Hsi-FengTu, (2012) also reported that TT in miR196a HNSCC patients seems to have a poorer prognosis. We found significant association between TT genotype in miR196a and miR149 and buccal mucosa. The earlier studies also identified the association between TT genotype in pre-miR-149 and the poor survival of HNSCC occurring on buccal mucosa. HsiFengTu, et al, also reported that HNSCC patients with TT genotypes are associated with chewing habitual risk. Similarly we also observed that patients with CT genotype in miR149 polymorphism and CC genotype in miR196a2 showed relationship with chewing habit of patients.

As cancer incidence is projected to increase over the decades there is a need for effective research on cancer prevention strategies. Some evidences suggest that altering the personal and dietary habits may be one of the approaches for reducing the cancer risk. Our study demonstrates that miR-196a $2 \mathrm{C}>\mathrm{T}$ and miR-149C $>\mathrm{T}$ polymorphisms may play a crucial role in the development of OSCC in South Indian population. These miR SNPs which are associated with the susceptibility to the oral cancer may be useful as biomarkers for the early prediction of the disease and for prevention strategies.

\section{Acknowledgements}

We are grateful to Dr.NTR University of Health Sciences for the Ph.D registration of Sushma P.S; we are also thankful to BMMRC and NIN for the facilities provided. We extend our thanks to the study groups for their cooperation.

\section{References}

Ahn DH, Rah H, Choi YK, et al (2013). Association of the miR$146 \mathrm{aC}>\mathrm{G}$, miR-149T $>C$, miR-196a2T $>C$, and $\mathrm{miR}-499 \mathrm{~A}>\mathrm{G}$ polymorphisms with gastric cancer risk and survival in the Korean population. Mol Carcinog, 52, 39-51.

Akkız H, Bayram S, Bekar A, et al (2011). A functional polymorphism in pre-microRNA-196a-2 contributes to the susceptibility of hepatocellular carcinoma in a Turkish population: a case-control study. J Viral Hepat, 18, 399-407.

Ambros V (2004). The functions of animal micro RNAs. Nature, 431, 350-5.

Aqeilan RI, Calin GA, Croce CM (2010). miR-15a and miR-16-1 in cancer: discovery, function and future perspectives.Cell Death Differ, 17, 215-20. 


\section{PS Sushma et al}

Bartel DP (2004). MicroRNAs: Genomics, Review Biogenesis, Mechanism, and Function. Cell, 116, 281-97.

Chu H, Wang M, Shi D, et al (2011). Hsa-miR-196a2 Rs11614913 polymorphism contributes to cancer susceptibility: evidence from 15 case-control studies. PLoS One, 6, 18108.

Chen H, Sun LY, Chen LL, et al (2012). A variant in microRNA$196 \mathrm{a} 2$ is not associated with susceptibility to and progression of colorectal cancer in Chinese. Intern Med J, 42, 115-119.

Dou T, Wu Q, Chen X, et al (2010). A polymorphism of microRNA196a genome region was associated with decreased risk of glioma in Chinese population. J Cancer Res Clin Oncol, 136, 1853-9.

Elango JK, Gangadharan P, Sumithra S, et al (2006). Trends of head and neck cancers in urban and rural India. Asian Pac J Cancer Prev, 7, 108-11.

George GP, Gangwar R, Mandal RK, et al (2011). Genetic variation in microRNA genes and prostate cancer risk in North Indian population. Mol Biol Rep, 38, 1609-15.

Gregory RI, Shiekhattar R (2005). MicroRNA biogenesis and cancer. Cancer Res, 65, 3509-3512.

Huang GL, Lu Y, Pu XX, et al (2013). Association study between miR149 gene polymorphism and nasopharyngeal carcinoma. Biomed Rep, 1, 599-603.

$\mathrm{Hu}$ Z, Chen J, Tian T, et al (2008). Genetic variants of miRNA sequences and non-small cell lung cancer survival. J Clin Invest, 118, 2600-8.

Jazdzewski K, Murray EL, Franssila K, et al (2008). Common SNP in pre-miR-146a decreases mature miR expression and predisposes to papillary thyroid carcinoma. Proc Natl Acad Sci U S A, 105, 7269-74.

Kwak PB, Iwasaki S, Tomari Y (2010). The microRNA pathway and cancer. Cancer Sci, 101, 2309-15.

Lewis, Benjamin P, Christopher B, et al (2005). Conserved seed pairing, often flanked by adenosines, indicates that thousands of human genes are microRNA targets, Cell, 120, 15-20.

Lin T, Ding Z, Li N, et al (2011). 2-Tellurium-bridged $\beta$-cyclodextrin, a thioredoxinreductase inhibitor, sensitizes human breast cancer cells to TRAIL-induced apoptosis through DR5 induction and NF-kB suppression. Carcinogenesis, 32, 154-167.

Liu Z, Li G, Wei S, et al (2010). Genetic variants in selected pre-mircroRNA genes and risk of squamous cell carcinoma of the head and neck. Cancer, 116, 4753-60.

Lovat, Francesca, Nicola Valeri, Carlo M, Croce (2011). MicroRNAs in the pathogenesis of cancer. Seminars Oncolo, 38,6 .

Okubo M, Tahara T, Shibata T, et al (2010). Association between common genetic variants in pre-microRNAs and gastric cancer risk in japanese population. Helicobacter, 15, 524-531.

Peng S, Kuang Z, Sheng C, et al (2010). Association of microRNA-196a-2 gene polymorphism with gastric cancer risk in a Chinese population. Dig Dis Sci, 55, 2288-93.

Rai R, Kulkarni V, Saranath D (2004). Genome wide instability scanning in chewing-tobacco associated oral cancer using inter simple sequence repeat PCR. Oral Oncol, 40, 1033-9.

Ryan BM, Robles AI, Harris CC (2010). Genetic variation in microRNA networks: the implications for cancer research. Nat Rev Cancer, 10, 389-402.

Salzman DW, Weidhaas JB (2013). SNPing cancer in the bud: MicroRNA and microRNA-target site polymorphisms as diagnostic and prognostic biomarkers in cancer. Pharmacol Ther, 137, 55-63.

Sassen S, Miska EA, Caldas C (2008). MicroRNA: implications for cancer. Virchows Arch, 452, 1-10.

Sheng Peng, Zhong shen Kuang, Chenyi Sheng, et al (2010). Association of miRNA 196a - 2 gene polymorphism with gastric cancer risk in a Chinese population. Dig Dis Sci, 55, 2288- 93 .

Shen J1, Ambrosone CB, DiCioccio RA, etal (2008). A functional polymorphism in the miR146a gene and age of familial breast/ovarian cancer diagnosis. Carcinogenesis, 29, 1963-1966.

Tu HF, Liu CJ, Chang CL, et al. (2012) The Association between Genetic Polymorphism and the Processing Efficiency of miR-149Affects the Prognosis of Patients with Head and Neck Squamous Cell Carcinoma. PLoS ONE, 7, 51606.

Wang K, Guo H, Hu H, Xiong G, et al (2010). A functional variation in pre-microRNA-196a is associated with susceptibility of esophageal squamous cell carcinoma risk in Chinese Han. Biomarkers, 15, 614-8.

Wang N, Li Y,Zhou RM, et al (2014). Hsa-miR-196a2 functional SNP is associated with the risk of ESCC in individuals under 60 years old. Biomarkers, 19, 43-48.

Xu T, Zhu Y, Wei QK, et al (2008). A functional polymorphism in the miR-146a gene is associated with the risk for hepatocellular carcinoma. Carcinogenesis, 29, 2126-31.

Xu Y, Liu L, Liu J, et al (2011). A potentially functional polymorphism in the promoter region of $\mathrm{miR}-34 \mathrm{~b} / \mathrm{c}$ is associated with an increased risk for primary hepatocellular carcinoma. Int $J$ Cancer, 128, 412-417.

Yang H, Dinney CP, Ye Y, et al (2008). Evaluation of genetic variants in microRNA-related genes and risk of bladder cancer. Cancer Res, 68, 2530-7.

Yoon KA, Yoon H, Park S, et al (2012). The prognostic impact of microRNA sequence polymorphisms on the recurrence of patients with completely resected non-small cell lung cancer. J Thorac Cardio Vas cSurg, 144, 794-807. 